\title{
Relationship between sperm concentration and the incidence of polyspermy in mouse embryos fertilized in vitro
}

\author{
Lynn R. Fraser*† and I. Maudlin* \\ *Clinical Research Centre, Watford Road, Harrow, Middlesex HAI 3UJ, and \\ $\dagger$ Department of Obstetrics and Gynaecology, University College Hospital, London WCIE 6DH, U.K.
}

\begin{abstract}
Summary. A dose-response relationship between the incidence of polyspermy and sperm concentration was found by analysing chromosome preparations of firstcleavage mouse embryos derived from fertilizations in vitro with 3 concentrations of mouse spermatozoa $\left(2 \times 10^{4}, 2 \times 10^{6}\right.$ and $\left.1 \times 10^{7} / \mathrm{ml}\right)$.
\end{abstract}

Although millions of spermatozoa are deposited in the mammalian female reproductive tract at the time of mating, only a small proportion (fewer than 1000 /oviduct) actually reach the site of fertilization (Blandau \& Odor, 1949; Braden, 1953; Braden \& Austın, 1954). In contrast, studies of the relationship between mammalian sperm concentration and fertility in vitro have indicated that a relatively high number of spermatozoa, generally $10^{5}-10^{7} / \mathrm{ml}$, must be present to ensure maximum fertility (Niwa \& Chang, 1974; Talbot, Franklin \& Fussell, 1974; Fraser \& Drury, 1975; Tsunoda \& Chang, 1975; Parkening \& Chang, 1976; Wolf \& Inoue, 1976). We have shown that the fertilization of mouse eggs in vitro results in an abnormally high incidence of polyploidy (Fraser, Zanellotti, Paton \& Drury, 1976), primarily due to polyspermy (Maudlin \& Fraser, 1977) and perhaps reflecting the high concentration of spermatozoa used (approximately $2 \times 10^{6} / \mathrm{ml}$ ). Positive correlations between sperm concentration and the incidence of polyspermy are not easily made from published data, even when the same experimental system is used. For example, Wolf \& Inoue (1976) reported an incidence of $5.9 \%$ polyspermy with $2 \times 10^{5}$ mouse spermatozoa/ml, yet Wolf \& Hamada (1976) found $25 \%$ polyspermy with $1 \times 10^{5}$ spermatozoa $/ \mathrm{ml}$. By contrast, we have shown our system to give reproducible levels of polyploidy with a concentration of approximately $2 \times 10^{6}$ spermatozoa/ml $(12 \cdot 8 \%$, Fraser et al., 1976; 15.4\%, Maudlin \& Fraser, 1977). The present study was designed to determine, by analysis of chromosome preparations of first cleavage embryos, whether variation in sperm concentration can alter the incidence of polyspermy in mouse embryos in a consistent way.

\section{Methods}

Egg donors were $(\mathrm{C} 57 \mathrm{BL} / 10 \times \mathrm{CBA}) \mathrm{F}_{1}$ females induced to superovulate with $7 \cdot 5$ i.u. PMSG (Gestyl: Organon) and, approximately 48 h later, 5 i.u. hCG (Pregnyl: Organon). Sperm donors were TO males. After a 20 min dispersal period, the suspensions of epididymal spermatozoa, prepared from 2 males with the media and methods described by Fraser \& Drury (1975), were diluted to concentrations of $2 \times 10^{4}, 2 \times 10^{6}$ and $1 \times 10^{7}$ spermatozoa/ml. Unfertilized eggs obtained $13 \mathrm{~h}$ after the hCG injection were added to the sperm suspensions, incubated for $6 \mathrm{~h}$ and then washed. The eggs in the lowest sperm concentration were treated with medium containing $2 \mathrm{mg}$ hyaluronidase (bovine testes, Type I: Sigma)/ml to remove cumulus cells still attached to the zona pellucida; this was unnecessary with the higher sperm concentrations. All eggs were then incubated overnight in $10^{-5} \mathrm{~mm}-$ vinblastine sulphate (Velbe: Lilly) and processed for chromosome analysis (Maudlin \& Fraser, 1977).

\section{Results}

Of the 6891 -cell embryos examined in this experiment, $617(89.5 \%)$ could be confidently assessed as diploid or polyploid. The male- and female-derived chromosome complements can be distinguished in 1-cell embryo preparations (Donahue, 1972; Hansmann 1973; Brewen, Payne, Jones \& Preston, 
Table 1. Incidence of polyspermy in first-cleavage mouse embryos fertilized in vitro in three different concentrations of spermatozoa

\begin{tabular}{|c|c|c|c|c|c|c|c|c|c|}
\hline \multirow[b]{3}{*}{ Exp. no. } & \multicolumn{9}{|c|}{ Sperm conc./ml } \\
\hline & \multicolumn{3}{|c|}{$2 \times 10^{4}$} & \multicolumn{3}{|c|}{$2 \times 10^{6}$} & \multicolumn{3}{|c|}{$1 \times 10^{7}$} \\
\hline & $\mathbf{N}$ & $\mathrm{n}$ & $\%$ & $\mathbf{N}$ & $\mathrm{n}$ & $\%$ & $\mathrm{~N}$ & n & $\%$ \\
\hline 1 & 44 & 1 & $2 \cdot 3$ & 34 & 3 & $8 \cdot 8$ & 33 & 3 & $9 \cdot 1$ \\
\hline 2 & 41 & 3 & $7 \cdot 3$ & 38 & 12 & 31.6 & 37 & 21 & $56 \cdot 8$ \\
\hline 3 & 29 & 0 & 0 & 45 & 5 & $11 \cdot 1$ & 53 & 3 & $5 \cdot 7$ \\
\hline 4 & - & - & - & 54 & 6 & $11 \cdot 1$ & 46 & 6 & $13 \cdot 0$ \\
\hline 5 & 90 & 7 & $7 \cdot 8$ & 37 & 5 & $13 \cdot 5$ & 36 & 4 & $11 \cdot 1$ \\
\hline Totals & 204 & 11 & $5 \cdot 4$ & 208 & 31 & 14.9 & 205 & 37 & $18 \cdot 0$ \\
\hline
\end{tabular}

$\mathrm{N}=$ no. of embryos examined; $\mathrm{n}=$ no. of polyspermic embryos.

1975) and we used this technique to determine the origin of the polyploidy detected in the present study. Of the 88 polyploid embryos found, 85 were triploid and 3 were trispermic tetraploids. Of the 85 triploids, $2(0.3 \%)$ were digynic in origin, $7(1.1 \%)$ were fertilized by diploid spermatozoa and the remaining $76(12.3 \%)$ were all dispermic. The 7 diploid spermatozoa were all found among embryos in Exp. 2, 4 occurring in the $2 \times 10^{6}$ sperm concentration and 3 in the $1 \times 10^{7}$ group.

The proportions of polyspermic 1-cell embryos found in the present study are shown in Table 1 . Because of the highly significant heterogeneity between experiments in the incidence of polyspermy at the two higher sperm concentrations, a simple comparison of the mean values for each group is not satisfactory. Instead, dose-response curves for each experiment were fitted by computer by using a weighted logistic analysis of the binomial proportions plotted against $\log _{10}$ of the sperm concentration. A test for parallelism showed that there was no significant difference between the slopes of the five regression lines $\left(\chi^{2}=11 \cdot 1\right.$; d.f. $8 ; P=$ N.S. $)$; the calculated common slope $(0.59 \pm 0 \cdot 14)$ value demonstrated a highly significant regression $(P=<0.001)$. This analysis shows clearly that the incidence of polyspermy among mouse embryos fertilized in vitro may be affected by altering the concentration of spermatozoa in the suspensions used.

These differences in the incidence of polyspermy with three sperm concentrations were not reflected in differing fertilities. The fertilization levels obtained in individual experiments for each sperm concentration (calculated from the number of eggs possessing second polar bodies before incubation in 'Velbe') were $61-98 \%\left(2 \times 10^{4}\right.$ spermatozoa $\left./ \mathrm{ml}\right), 71-100 \%\left(2 \times 10^{6}\right.$ spermatozoa $\left./ \mathrm{ml}\right)$ and $79-97 \%$ $\left(1 \times 10^{7}\right.$ spermatozoa/ml).

Of the 617 embryos scored for polyploidy, 554 (90\%) gave sufficiently well spread preparations to allow the incidence of aneuploidy to be assessed. Six aneuploid embryos, 3 monosomic and 3 trisomic, were found among the 554 scored $(1 \cdot 1 \%)$.

\section{Discussion}

Studies on sperm concentration as a critical factor in the successful fertilization of mammalian eggs in vitro have concentrated on the effect of sperm numbers in relation to the efficiency of the technique, as measured by the resultant fertility of the eggs. By using a wide range of sperm concentrations which gave equally high levels of fertility, we have determined the incidence of polyspermy and shown a clear dose-response relationship. The fertilization obtained with the lowest sperm concentration $\left(2 \times 10^{4} / \mathrm{ml}\right)$ was considerably higher than previously reported (Fraser \& Drury, 1975), presumably reflecting a general improvement in the fertility of TO sperm suspensions in this system (Fraser \& Drury, 1976). As might have been expected, alteration of sperm concentration had no effect on the incidence of either male or female aneuploidy. All 7 diploid spermatozoa were found in a single experiment, suggesting that these aberrant spermatozoa came from an individual male producing a relatively high proportion of diploid gametes because only 2 males were used for each experiment 
We have already shown that the dose of PMSG can influence the incidence of polyspermy in mouse eggs fertilized in vitro (Maudlin \& Fraser, 1977). Since all the eggs used in the present experiment were obtained after treatment with a single PMSG dose, any effects due to the hormone should have been the same in all 3 groups. The dose-response to sperm concentration may therefore be explained as follows. Firstly, the hormone may alter the zona pellucida so that more spermatozoa than normal can enter the perivitelline space of the unfertilized egg, thereby increasing the chances of two or more spermatozoa fusing with the vitellus. Secondly, the greater the sperm concentration the greater the probability that more than one spermatozoon will penetrate the zona. The majority of the polyspermic embryos found in the present experiment were dispermic, suggesting that the vitelline block to polyspermy was functioning but that in many eggs 2 spermatozoa were able to fertilize the egg at approximately the same time. Indeed, when 2 spermatozoa had fertilized an egg, the two sets of male chromosomes usually showed similar degrees of contraction indicating that they had penetrated the egg almost simultaneously. This hypothesis is supported by the work of Braden, Austin \& David (1954) which showed that the 2 fertilizing spermatozoa in dispermic rat eggs usually entered the egg at opposite hemispheres. This suggested that sperm penetration set up a propagated reaction around the egg, leaving only a short period of time for a second spermatozoon, if present, to fuse with the egg.

After mating and fertilization in vivo, the incidence of polyploidy in the mouse is low, about $1 \%$ (Donahue, 1972; Ford \& Evans, 1973) and this may reflect the low number of spermatozoa which reach the site of fertilization (Braden \& Austin, 1954). The present work indicates that it should be possible to determine an optimal sperm concentration for fertilization in vitro which would yield maximal fertility and minimal polyspermy.

We thank Linda Drury and Gillian Haynes for technical assistance and Dr C. E. Ford for his interest in this work. One of us (I.M.), a visiting worker at the Clinical Research Centre, is a member of the M.R.C. External Scientific Staff.

\section{References}

Blandau, R.J. \& ODOR, D.L. (1949) The total number of spermatozoa reaching various segments of the reproductive tract in the female albino rat at intervals after insemination. Anat. Rec. 103, 93-109.

BRADEN, A.W.H. (1953) Distribution of sperms in the genital tract of the female rabbit after coitus. Aust. J. biol. Sci, 6, 693-705.

Braden, A.W.H. \& Austin, C.R. (1954) The number of sperms about the eggs in mammals and its significance for normal fertilization. Aust. J. biol. Sci. 7, 543-551.

Braden, A.W.H., Austin, C.R. \& David, H.A. (1954) The reaction of the zona pellucida to sperm penetration. Aust. J. biol. Sci. 7, 391-409.

Brewen, J.G., Payne, H.S., Jones, K.P. \& Preston, R.J. (1975) Studies on chemically induced dominant lethality. 1. The cytogenetic basis of MMS-induced dominant lethality in post-meiotic male germ cells. Mutation Res. 33, 239-250.

Donahue, R.P. (1972) Cytogenetic analysis of the first cleavage division in mouse embryos. Proc. natn. Acad. Sci. U.S.A. 69, 74-77.

FORD, C.E. \& EvaNS, E.P. (1973) Non-expression of genome unbalance in haplophase and early diplophase of the mouse and incidence of karyotype abnormality in post-implantation embryos. In Chromosomal Errors in Relation to Reproductive Failure, pp.
271-285. Eds A. Boué \& C. Thibault. INSERM, Paris.

Fraser, L.R. \& DRURY, L.M. (1975) The relationship between sperm concentration and fertilization in vitro of mouse eggs. Biol. Reprod. 13, 513-518.

Fraser, L.R. \& DruRY, L.M. (1976) Mouse sperm genotype and the rate of egg penetration in vitro. $J$. exp. Zool. 197, 13-20.

Fraser, L.R., Zanellotti, H.M., Paton, G.R. \& DRURY, L.M. (1976) Increased incidence of triploidy in embryos derived from mouse eggs fertilized in vitro. Nature, Lond. 260, 39-40.

HansmanN, I. (1973) Induced chromosomal aberrations in pronuclei, 2-cell stages and morulae of mice. Mutation Res. 20, 353-367.

MAUdLIN, I. \& FRASER, L.R. (1977) The effect of PMSG dose on the incidence of chromosomal anomalies in mouse embryos fertilized in vitro. J. Reprod. Fert. 50, 275-280.

Niwa, K. \& Chang, M.C. (1974) Optimal sperm concentration and minimum number of spermatozoa for fertilization in vitro of rat eggs. J. Reprod. Fert. 40, 471-474.

Parkening, T.A. \& Chang, M.C. (1976) Strain differences in the in vitro fertilizing capacity of mouse spermatozoa as tested in various media. Biol.

DowReprod. 15,0647i-653.entifica.com at $04 / 26 / 2023$ 10:37:25AM 
Talbot, P., Franklin, L.E. \& Fussell, E.N. (1974) The effect of the concentration of golden hamster spermatozoa on the acrosome reaction and egg penetration in vitro. J. Reprod. Fert. 36, 429-432.

Tsunoda, Y. \& Chang, M.C. (1975) Penetration of mouse eggs in vitro: optimal sperm concentration and minimal number of spermatozoa. J. Reprod. Fert. 44, 139-142.
Wolf, D.P. \& HamadA, M. (1976) Age-dependent losses in the penetrability of mouse eggs. J. Reprod. Fert. 48, 213-214.

Wolf, D.P. \& INOUE, M. (1976) Sperm concentration dependency in the fertilization and zonae sperm binding properties of mouse eggs inseminated in vitro. J. exp. Zool. 196, 27-38.

Received 20 May 1977 